\title{
Synthesis of Au, Ag, Curcumin Au/Ag, and Au-Ag Nanoparticles and Their Nonlinear Refractive Index Properties
}

\author{
F. Abdulwahab, ${ }^{1}$ F. Z. Henari, ${ }^{1}$ S. Cassidy, ${ }^{1}$ and K. Winser ${ }^{2}$ \\ ${ }^{1}$ Department of Medical Sciences, Royal College of Surgeons in Ireland, Medical University of Bahrain, Building 2441, \\ Road 2835, Block 228, Busaiteen, Bahrain \\ ${ }^{2}$ Department of Physiology \& Medical Physics, Royal College of Surgeons in Ireland, 123 St. Stephen's Green, Dublin 2, Ireland
}

Correspondence should be addressed to F. Abdulwahab; fabdulwahab@rcsi.ie

Received 12 May 2016; Revised 25 July 2016; Accepted 23 August 2016

Academic Editor: Giuseppe Compagnini

Copyright $(2016$ F. Abdulwahab et al. This is an open access article distributed under the Creative Commons Attribution License, which permits unrestricted use, distribution, and reproduction in any medium, provided the original work is properly cited.

\begin{abstract}
Nanoparticles of gold and silver were prepared by a reduction method and by employing green chemistry principles such as using curcumin as a reducing and a stabilizing agent. The formation of nanoparticles was confirmed by UV-Vis absorption spectra and TEM. Mie theory was used to determine the particle sizes. The nonlinear refraction and absorption properties of the particles were measured using the z-scan technique. A large value of third-order nonlinearities was obtained using the nanoparticles produced.
\end{abstract}

\section{Introduction}

Metallic nanoparticles have attracted a huge interest because their physical and chemical properties are different from those of their bulks [1]. As a result they are ideal candidates for many applications, including electronics and optoelectronic devices, and in medical applications such as diagnosis, drug delivery, and therapy. Metallic nanoparticles form district energy levels, which are shown in the linear absorption spectra by a broad band absorption. This manifests as surface plasmon resonance, which does not exist in the case of bulk materials. Nanoparticles have a large number of conduction electrons. There are more atoms at the surface of the nanoparticles than the number of atoms inside, and thus this property gives rise to interesting properties due to the interaction between nanoparticles and surrounding media. The strong interaction of nanoparticles with light waves takes place because the conduction electrons on the metal surface undergo a combined oscillation when excited by light at specific wavelengths. The collective oscillation of excited electrons in the conduction band also known as surface plasmon resonance (SPR) and the surface area to volume ratio leads to a strong interaction with the incoming electromagnetic wave to enhance the local field, thus boosting the nonlinear optical properties of these materials. The optical properties of nanoparticles are strongly dependent on the particle size and shape and dielectric properties of the matrix. These properties have a vital role in developing optical devices and in the biomedical field. It has been suggested that, in the vicinity of the SPR absorption region, the nanoparticles exhibit a large value of optical nonlinearities. Different techniques have been used to investigate the optical nonlinearities such as four-wave mixing [2], nonlinear interferometry [3], and $\mathrm{Z}$-scan $[4,5]$. Z-scan is the most popular technique due to its simplicity and it allows the determination of the sign and the magnitude of nonlinear optical properties, such as nonlinear refractive index and nonlinear absorption in a single scan. Many reports have described the nonlinear properties and behavior demonstrated by nanoparticles and their dependence on sizes, shapes, and surrounding medium [6-9].

In this paper we report the nonlinear behavior of gold, silver, curcumin-gold, curcumin-silver, and silver-gold nanoparticles which were prepared by the chemical reduction method and green synthesis. The nonlinear refractive index and nonlinear absorption of these samples were measured using the $\mathrm{z}$-scan technique with $\mathrm{cw}$ argon-ion laser beam at $488 \mathrm{~nm}$ and $514 \mathrm{~nm}$. The magnitude of the nonlinear 
properties was measured with different synthesis methods and found to have no relationship between the values of the nonlinearities and the synthesis method.

\section{Synthesis of Nanoparticles}

Starting materials were purchased from Sigma Aldrich and used without any further purifications. Distilled water was used to prepare the solutions of the reacting materials. The Au colloid was prepared by chemical reduction according to the procedure given in [10]. $20 \mathrm{~mL}$ of $1 \mathrm{mM} \mathrm{HAuCl}_{4}$ solution was stirred and heated to boiling temperature. Then, $2 \mathrm{~mL}$ of $1 \%$ trisodium citrate was added to the solution. The solution was left boiling until color changed to deep red. In this reaction, gold is reduced from $\mathrm{Au}^{+3}$ to $\mathrm{Au}^{0}$ by the trisodium citrate. Chemical equation is given as follows [11]:

$$
\begin{aligned}
& 2 \mathrm{HAuCl}_{4}+4 \mathrm{Na}_{3} \mathrm{C}_{6} \mathrm{H}_{5} \mathrm{O}_{7} \\
& \quad \longrightarrow \mathrm{H}_{2}+2 \mathrm{Au}^{0}+4 \mathrm{CO}_{2}+4 \mathrm{NaC}_{5} \mathrm{H}_{5} \mathrm{O}_{5}+8 \mathrm{NaCl}
\end{aligned}
$$

The gold nanoparticles were synthesized using a green chemistry method. In this method the gold nanoparticles were prepared by using curcumin as a reducing and stabilizing agent [12]. A $0.11 \mathrm{~g}$ of curcumin was dissolved in $15 \mathrm{~mL}$ of DMSO and the $\mathrm{pH}$ of the solution was increased to 9.3 using $\mathrm{Na}_{2} \mathrm{CO}_{3}$ (dissolved $0.24 \mathrm{~g}$ in $15 \mathrm{~mL}$ of water). $1 \mathrm{mM}$ of $\mathrm{HAuCl}_{4}$ was added dropwise with shaking to $2 \mathrm{~mL}$ of curcumin, until the color changes from yellow to colorless, black, and burgundy red. According to Sindhu et al. [12], the formation of curcumin conjugated gold nanoparticles includes six steps of deprotonation, reduction, nucleation, growth, cleavage, and maturation. First curcumin $\mathrm{Cur}^{-3}$ is formed after the dissociation of hydrogen atoms from enolic curcumin hydroxyl groups. Then gold is reduced by the electrons on the $\mathrm{O}^{-}$from $\mathrm{Au}^{+3}$ to $\mathrm{Au}^{0}$. The $\mathrm{Au}^{0}$ atoms form clusters and those clusters cleave into smaller fragments due to instability and finally spherical and solid nanoparticles are formed.

Ag nanoparticles were prepared using chemical reduction method [13]. $84.9 \mathrm{mg}$ of silver nitrate $\left(\mathrm{AgNO}_{3}\right)$ was dissolved in $500 \mathrm{~mL}$ of distilled water. The solution was stirred and heated to boiling temperature and $5 \mathrm{~mL}$ of trisodium citrate ( $1 \mathrm{~g}$ dissolved in $100 \mathrm{~mL}$ of water) was added to the solution. The solution was left to boil for 2 hours and color changed to greenish. In this reaction silver nitrate is reduced by trisodium citrate to form silver nanoparticles. Chemical equation is given as follows [14]:

$$
\begin{aligned}
4 \mathrm{Ag}^{+} & +\mathrm{C}_{6} \mathrm{H}_{5} \mathrm{O}_{7} \mathrm{Na}_{3}+2 \mathrm{H}_{2} \mathrm{O} \\
& \longrightarrow 4 \mathrm{Ag}^{0}+\mathrm{C}_{6} \mathrm{H}_{5} \mathrm{O}_{7} \mathrm{H}_{3}+3 \mathrm{Na}^{+}+\mathrm{H}^{+}+\mathrm{O}_{2} \uparrow
\end{aligned}
$$

Another method was used to prepare Ag nanoparticles using curcumin as reducing agent. In this method, $1 \mathrm{~g}$ of curcumin was dissolved in $100 \mathrm{~mL}$ of DMSO. A solution of $7 \mathrm{~mL}$ of $1 \mathrm{mM} \mathrm{AgNO}_{3}$ was heated to boiling temperature with stirring followed by the addition of $3 \mathrm{~mL}$ of the prepared curcumin solution. Heating was continued for 5 minutes. Curcumin acts as reducing agent. It is worth mentioning that the most significant aspect of the above procedure is that the maintenance $\mathrm{pH}$ during the synthesis process is not required.

$\mathrm{Ag} / \mathrm{Au}$ (core/shell) nanoparticles were prepared using gripe water according to the procedure given in [15]. In a flask, $2 \mathrm{~mL}$ of $0.3 \mathrm{mM} \mathrm{AgNO}_{3}$ was mixed with $10 \mathrm{~mL}$ of gripe water. In another flask, $2 \mathrm{~mL}$ of $0.3 \mathrm{mM}$ of $\mathrm{HAuCl}_{4}$ was left stirring. Under continuous stirring the mixture of gripe water and $\mathrm{AgNO}_{3}$ was added to $\mathrm{HAuCl}_{4}$ and left stirring for 22 hours. In this method $\mathrm{Au}$ and $\mathrm{Ag}$ nanoparticles are reduced by hydrolyzed sucrose that is present in the gripe water, while they are stabilized by sodium benzoate, sodium methyl paraben, sodium propylparaben, and bronopol.

\section{Results and Discussions}

3.1. Absorption Spectra. UV-Vis spectrometer Shimadzu UV1800 was used to record absorption spectra of all the samples. The UV-Vis absorption spectrum for $\mathrm{Au}$ and Ag nanoparticles is shown in Figure 1(a). The spectra for $\mathrm{Au}$ and Ag nanoparticles are characterized by a broad band in the visible region with a surface SPR peak at $517 \mathrm{~nm}$ and $414 \mathrm{~nm}$, respectively. The sharp peaks indicate the formation of spherical nanoparticles. The stability of the nanoparticles was monitored by observing the position of the absorption peak over weeks. No obvious shift in the absorption peak was observed. If the particle increases in size, the peak absorption will shift to longer wavelength (red shift) [16]; however, no such behavior was observed. The Transmission Electron Microscopy (TEM) image of the Au particles is shown in Figure 1(b). It can be seen from the figure that Au nanoparticles are spherical in shape with smooth surface. The particle size was determined using Image J $1.5 \mathrm{~g}$ software by calculating the diameter $(d)$ in pixels. Pixels were converted to nanometers by applying the scale of the image. The diameter $(d)$ of each nanoparticle was marked manually and found to have a range from 9 to $23 \mathrm{~nm}$ with high yield of size $12 \mathrm{~nm}$, Figure 1(b). It was shown that the full width at half maximum of the absorption spectrum is related to the particle sizes [17]. The relative narrow band of absorption observed in this case may be used as an indication of the formation of small sizes of $\mathrm{Au}$ particle. It is worth mentioning that the TEM images were taken two weeks after synthesis and no aggregation was observed.

Figure 2 shows the UV-Vis absorption spectra of $\mathrm{Au}$, curcumin-Au, Ag, curcumin-Ag, and (core-shell) Au-Ag. The spectra are characterized by a broad band in the visible region with a plasmon resonance peak at 517, 536, 414, 436, and $472 \mathrm{~nm}$, respectively. For curcumin-Au and curcumin-Ag, the formation of the nanoparticles is characterized by the disappearance of the absorbance maximum peak $(430 \mathrm{~nm})$ of curcumin and the shift of SPR absorbance peak from $517 \mathrm{~nm}$ for Au particles to $536 \mathrm{~nm}$ for curcumin-Au and the shift SPR peak from 430 for Ag particles nm to 436 for Ag-curcumin. This shifting indicates coupling between curcumin-Au and curcumin-Ag. The SPR shift is also observed for Ag-Au $(472 \mathrm{~nm})$ in comparison to SPR peak for $\mathrm{Ag}(430 \mathrm{~nm})$. 


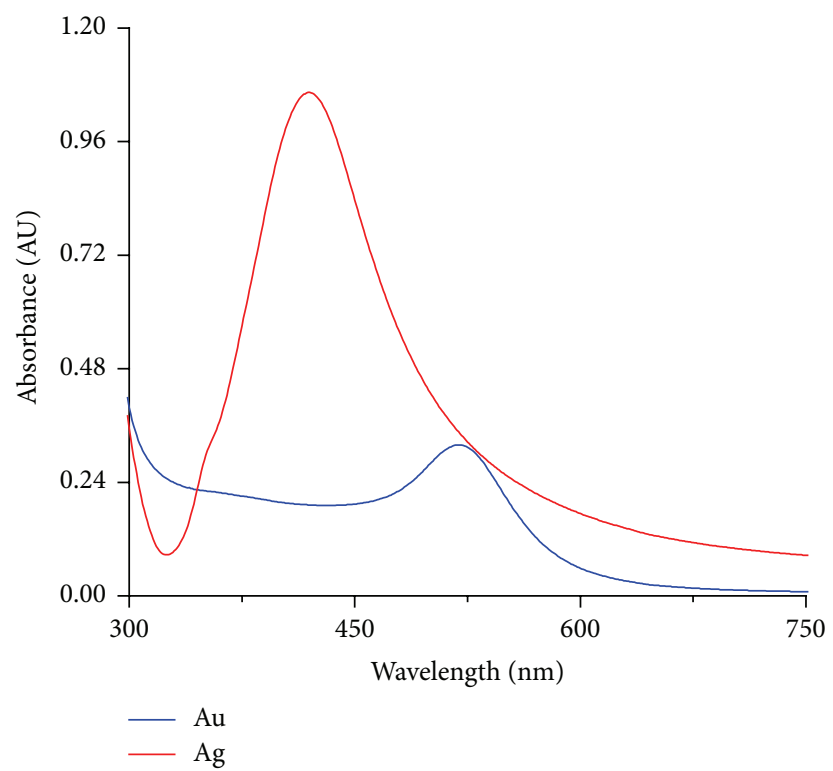

(a)
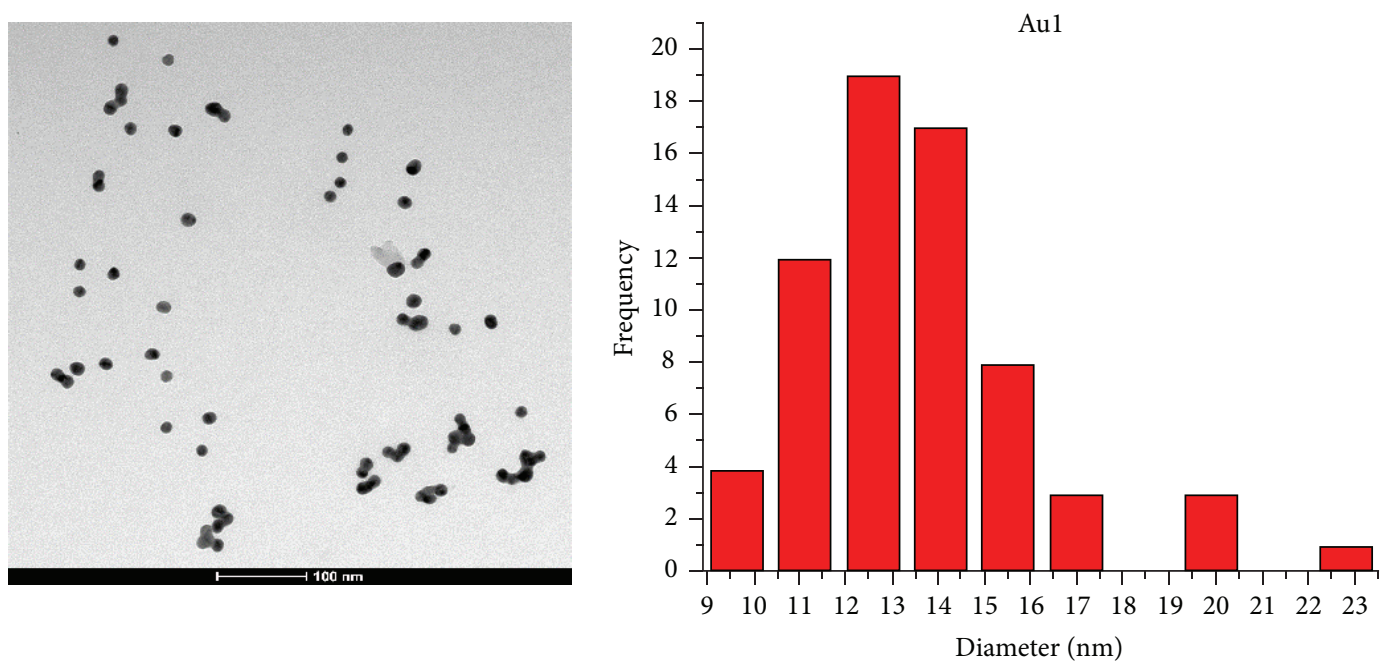

Frequency

(b)

FIGURE 1: (a) UV-Vis absorption spectrum for Au (blue) and for Ag (red) nanoparticles in water. (b) TEM image and size distribution for Au nanoparticles.

Because facilities for measuring the nanoparticle sizes were not available to the investigators, we used the Mie theory to determine the particles size of colloidal nanoparticles. For this we used a computer simulation program (Mie plot v4.5). The procedure for calculation was performed as described in [18] because the position of the SPR peak depends on the diameter of nanoparticles. A number of calculations were performed at different diameters of nanoparticles and the calculated data was fitted to the experimental absorption data, using Origin 9 software; see Figure 2. The best fit between calculated data and the experimental absorption spectra was found for each particle and estimated values of diameters are given in Table 1 . It should be noted that the size of the shell/core particle is larger than the metal particle, which indicates the reaction of curcumin with metals.

3.2. Z-Scan Techniques. The nonlinear refractive index $n_{2}$ is given by $n=n_{0}+n_{2} I$, where $n_{0}$ is the linear refractive index and $I$ is the intensity of incident light. The nonlinear absorption coefficient $\alpha$ is given by $\alpha=\alpha_{0}+\beta I$, where $\alpha_{0}$ is the linear absorption coefficient, $\beta$ is a nonlinear absorption coefficient, and $I$ is the intensity of incident light. Z-scan technique [19] was used to measure the nonlinear refractive index and the nonlinear absorption coefficient of nanoparticles. This technique relies on the fact that the intensity varies along the axis of the convex lens and is maximum at the focus. 

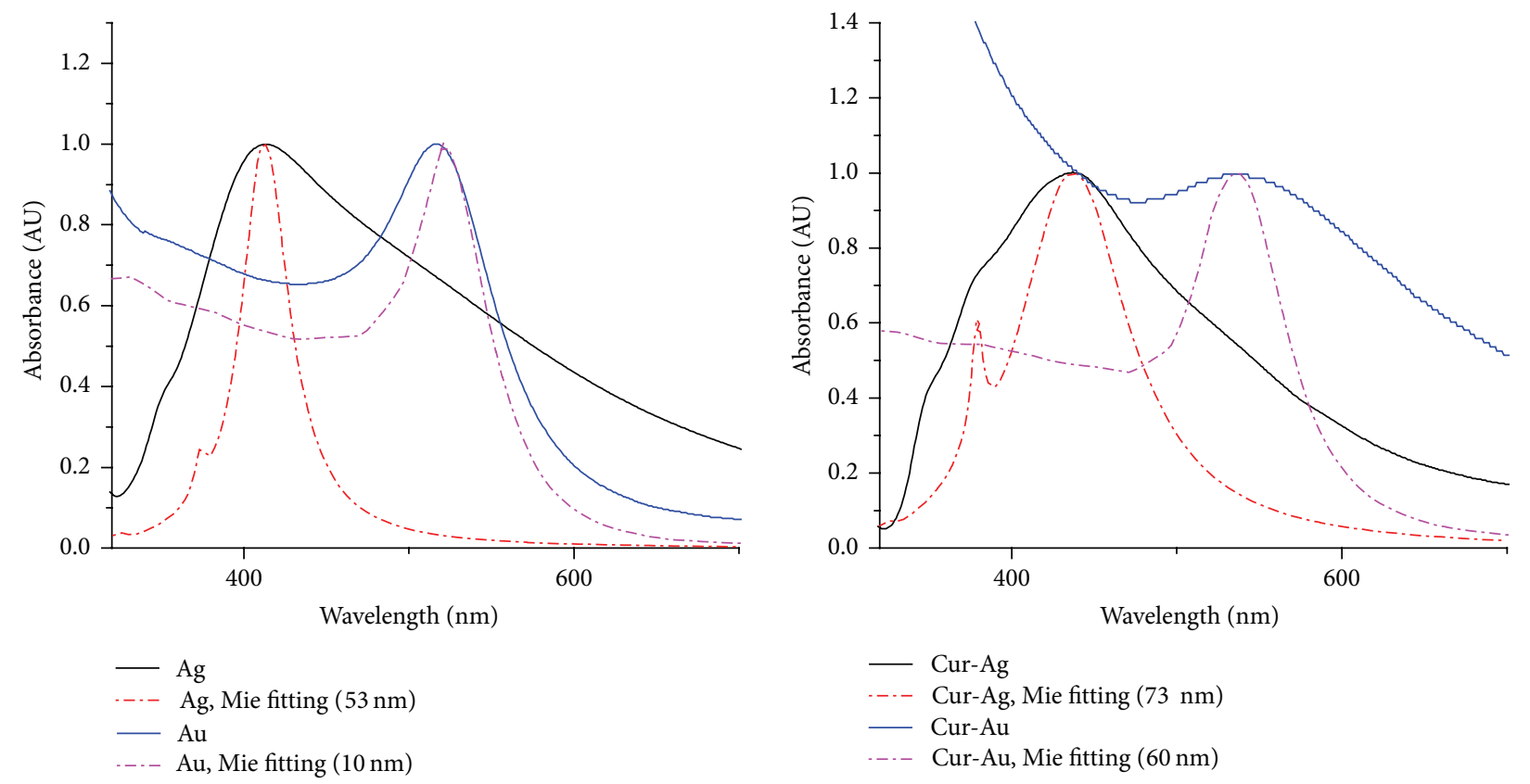

FIGURE 2: Comparison between calculated spectra using the Mie theory and experimental spectra for Au and Curcumin-Au and Ag and Curcumin-Ag.

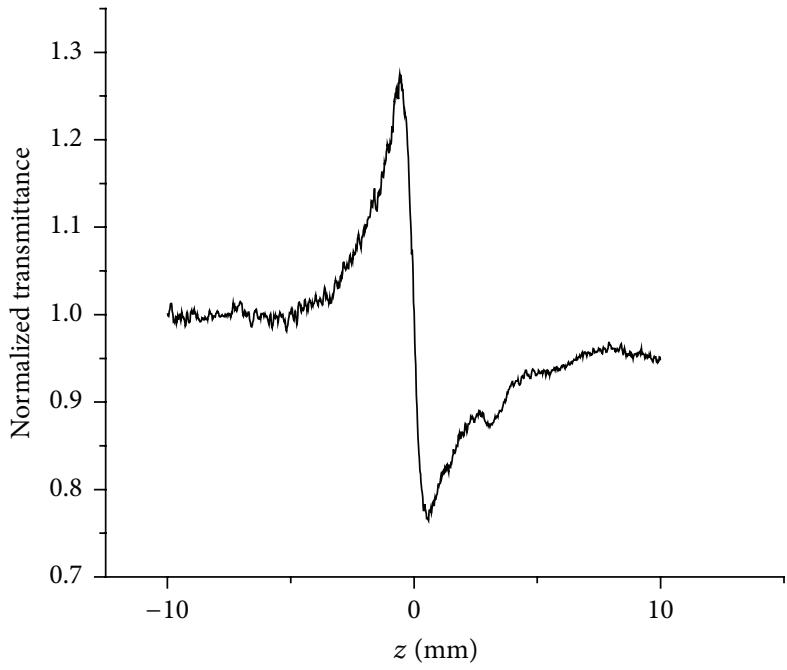

- Ag

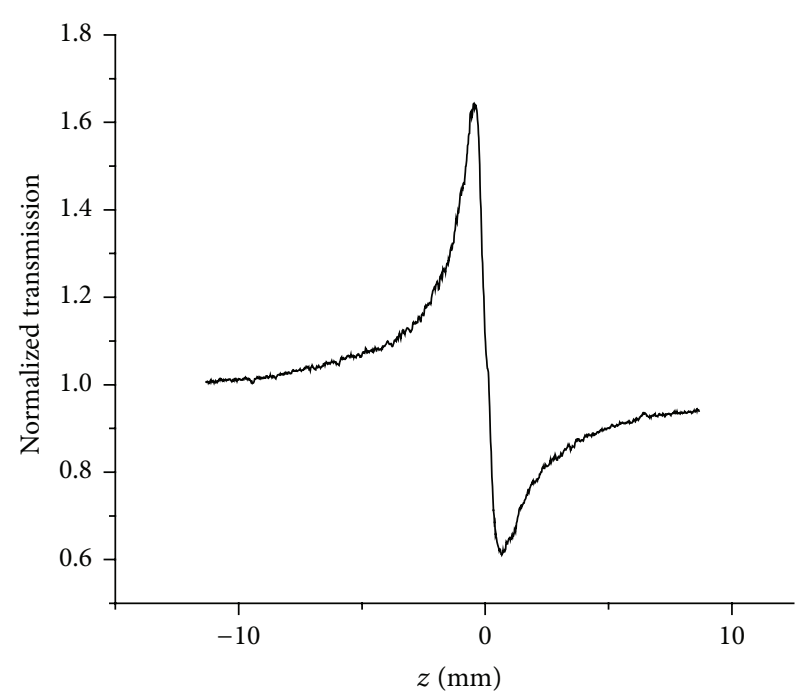

- Cur-Au

(a)

(b)

Figure 3: Closed aperture z-scan response for Ag (a) and (b) for Cur-Au.

Hence, by shifting the sample through the focus, the intensity dependence can be measured as a change in transmission. In the $\mathrm{z}$-scan procedure, the transmission for the sample was measured with and without an aperture in the far-field of the lens as the sample moved through the focal point. This enables the nonlinear refractive index (closed aperture) to be separated from that of the nonlinear absorption (open aperture).

The experiment was performed with an air-cooled argonion laser beam operating at $488 \mathrm{~nm}$ and $514 \mathrm{~nm}$ with adjusting power between 15 and $30 \mathrm{~mW}$. The beam was focused to a beam waist of $20 \mu \mathrm{m}$ with a lens of $10 \mathrm{~cm}$ focal length, giving a typical power density range of $2.38 \times 10^{7}-4.78 \times 10^{7} \mathrm{~W} / \mathrm{m}^{2}$. The transmission for the samples was measured with and without aperture in the far-field of the lens as the samples moved through the focal point.

Figure 3 shows a typical normalized transmission at wavelength $488 \mathrm{~nm}$ (closed z-scan) for samples Ag and cur$\mathrm{Au}$ as a function of the sample position. The normalized transmittance curve for the samples was characterized by 
TABLE 1: Synthesized nanoparticles sizes measured with Mie plot.

\begin{tabular}{lc}
\hline Type of NPs & Size $(\mathrm{nm})$ \\
\hline $\mathrm{Au}$ & 10 \\
$\mathrm{Ag}$ & 55 \\
Curcumin-Au & 60 \\
Curcumin-Ag & 73 \\
\hline
\end{tabular}

TABLE 2: Showing the values of $\Delta T_{p-v}$, nonlinear index of refraction, and nonlinear absorption coefficient.

\begin{tabular}{lcccc}
\hline Sample & $\begin{array}{c}\lambda \\
(\mathrm{nm})\end{array}$ & $\Delta T_{p-v}$ & $\begin{array}{c}n_{2} \times 10^{-12} \\
\left(\mathrm{~m}^{2} \mathrm{~W}^{-1}\right)\end{array}$ & $\begin{array}{c}\beta \times 10^{-5} \\
\left(\mathrm{~m} \mathrm{~W}^{-1}\right)\end{array}$ \\
\hline $\mathrm{Au}$ & 514 & 1.09 & -3.22 & -7.87 \\
$\mathrm{Cur}-\mathrm{Au}$ & 514 & 1.02 & -3.26 & +8.58 \\
$\mathrm{Ag}$ & 488 & 0.50 & -1.61 & +3.52 \\
$\mathrm{Cur}-\mathrm{Ag}$ & 488 & 3.84 & -8.82 & +5.45 \\
$\mathrm{Au}-\mathrm{Ag}$ & 488 & 0.61 & -0.574 & -2.7 \\
\hline
\end{tabular}

a preface peak followed by a postfocal valley. This peakvalley configuration implies that the nonlinear refractive index of solution is negative $\left(n_{2}<0\right)$ (self-defocusing). Similar characteristics were shown by other samples studied. The asymmetry in the closed $\mathrm{z}$-scan curve is the signature of thermal contribution to nonlinear refractive index and is explained below. The values of the differences between normalized peak-valley transmittance $\left(\Delta T_{p-v}\right)$ for the samples are shown in Table 2 . It is possible from the peak to valley variation of the measured transmittance to calculate the nonlinear refractive index $n_{2}$.

The difference between normalized peak-valley transmittance $\Delta T_{p-v}$ is given by

$$
\Delta T_{p-v}=0.406(1-S)^{0.25}|\Delta \phi|,
$$

where $\Delta|\phi|$ is the on-axis nonlinear phase shift at the focus and $S$ is the linear transmittance of the aperture and is given by

$$
S=1-\exp \left(-\frac{2 r_{a}^{2}}{w_{a}^{2}}\right),
$$

where $r_{a}$ is the radius of the aperture and $w_{a}$ is the radius of the laser at the entrance of the aperture. The nonlinear phase shift is given by

$$
\Delta|\phi|=\frac{2 P L_{\mathrm{eff}}}{\lambda w_{0}^{2}} n_{2},
$$

where $n_{2}$ is the nonlinear refractive index, $P$ is the laser power, $\lambda$ is the laser wavelength, and $L_{\text {eff }}=(1-\exp (-\alpha L)) / \alpha$, where $\alpha$ is the linear absorption coefficient at $488 \mathrm{~nm}, L$ is the sample thickness, and $L_{\text {eff }}$ is the effective thickness of the sample.

Equations (3) and (5) were used to calculate the value of nonlinear refractive index $n_{2}$. The values of $n_{2}$ are shown in Table 2. These values are the average of three close $\mathrm{z}$-scans

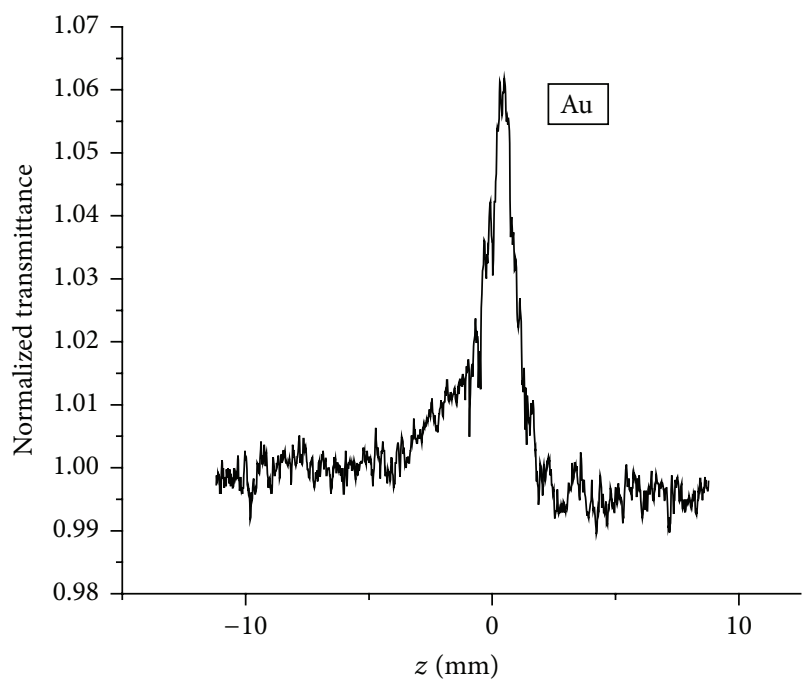

Figure 4: Open aperture Z-scan response for Au nanoparticle at $514 \mathrm{~nm}$.

with an estimated error of $10 \%$. The values reported here are in the same order as values reported in [20].

Figure 4 shows a typical normalized transmission at wavelength $514 \mathrm{~nm}$ (open $\mathrm{z}$-scan) for sample Au as a function of the sample position. The normalized transmittance curve for the samples was characterized by a maximum transmission at focus. This shows that the sample exhibits a saturation absorption (SA). A similar behavior was observed for Ag. Figure 5 shows the normalized transmission (open $\mathrm{z}$-scan) for cur-Au and cur-Ag samples. The normalized transmission was characterized by a minimum transmission at the focus. Thus the samples exhibit a reverse saturation absorption (RSA). Refractive indices of the matrix around nanoparticles play important roles in tuning the SPR band and in turn the nonlinear properties. This may explain the observed RSA for cur-Au and cur-Ag samples. Figure 6 shows an open z-scan for shell/core Ag-Au. The transmission is characterized by saturation absorption (SA).

For open aperture z-scan, the nonlinear absorption coefficient $(\beta)$ is related to sample transmittance $T$ at focus, by [19]

$$
T=1+\frac{\beta I L_{\mathrm{eff}}}{2 \sqrt{2}}
$$

Equation (6) was used to calculate the value of nonlinear absorption coefficient $\beta$. The values of $\beta$ obtained for the samples are shown in Table 2 . These values are the average of three open $\mathrm{z}$-scans with an estimated error of $10 \%$. The values reported here are in agreement with previously reported values $[20,21]$.

The process leading to the observed SA and RSA can be explained by considering band gap structures of noble metals $[21,22]$. The optical properties of metals are influenced by the localization of electrons (of) in the $d$ bands and by quasi free electrons in the sp conduction bands. The Fermi level lies between 2 and $5 \mathrm{eV}$ above the $d$-bands. Electron transition between the $d$ bands and the conduction bands can occur for 

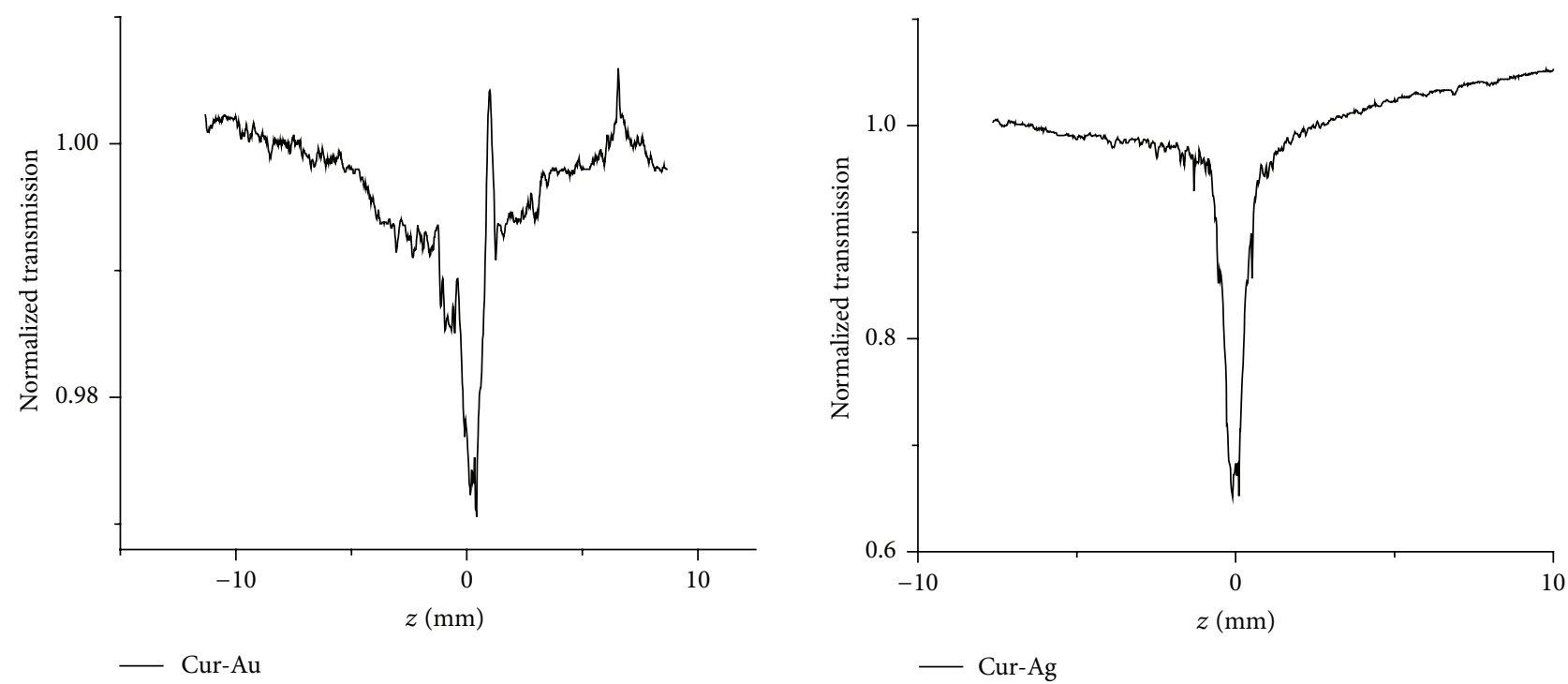

FIgURE 5: Open aperture z-scan response for cur-Au at $514 \mathrm{~nm}$ and cur-Ag at $488 \mathrm{~nm}$.

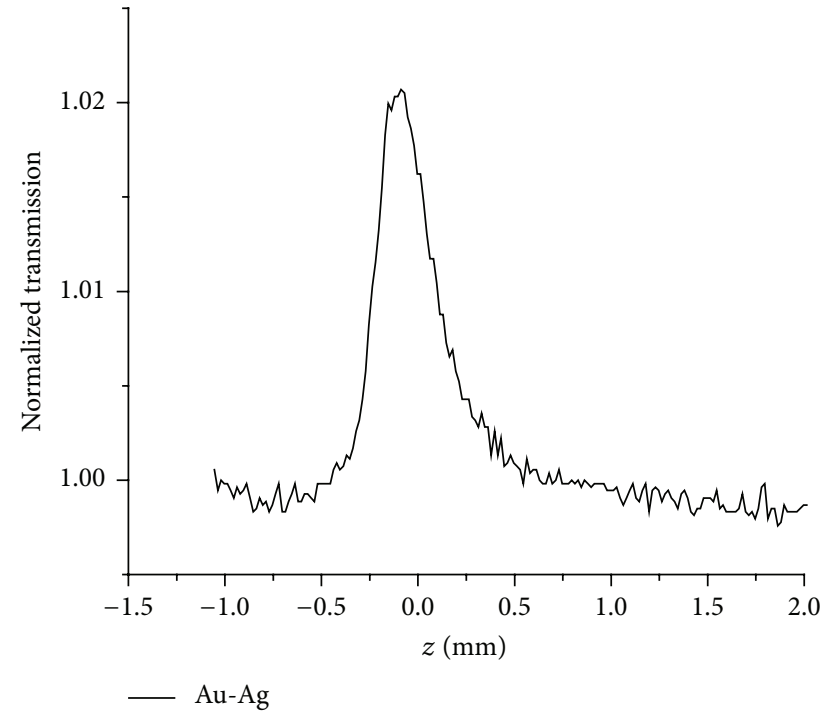

FIgURE 6: Open aperture z-scan response for $\mathrm{Au}-\mathrm{Ag}$ at $488 \mathrm{~nm}$.

photon energy in the visible region. The processes involved in nonlinear optical properties are surface plasmon absorption, free carrier absorption, and two-photon absorption. The excitation wavelengths used for investigation of the nonlinear absorption were $488 \mathrm{~nm}$ and $514 \mathrm{~nm}$, which are almost in the vicinity of the SPR peak of Au and Ag nanoparticles. In this case the main effect involves the excitation of the electrons from the SPR band. The excited electrons interact with the electric field of the incident beam leading to higher order oscillations, which leads to a difference in frequency between SPR excited electrons and unexcited electrons. The electrons in the original SPR band that cannot further absorb radiation results in SA behavior. The SA behavior for Au particles is shown in Figure 4. Similar behavior was observed for Ag nanoparticles. For cur-Au and cur-Ag particles RSA were observed. The RSA behavior can be explained by two-step resonant two-photon absorption (TSA) where in the first step electrons from $d$ bands are excited to Fermi level by absorbing a photon of energy $(\lambda=488 \mathrm{~nm}, E=2.7 \mathrm{eV}$, and $\lambda=514 \mathrm{~nm}$, $E=2.4 \mathrm{eV}$ ). In the second step electrons are transferred from the Fermi level to the conduction band by absorbing a second photon.

The process leading to refractive index change involves the excitation of the electrons from the SPR band. The excited electrons interact with the electric field of the incident beam leading to higher order oscillations. The excited hot electrons (electrons with higher energy than Fermi energy) are thermalized by dissipating the excess to the surroundings. The excess thermal energy increases the surrounding temperature and generates a temperature gradient. This temperature gradient leads to a variation in refractive index, which is called a thermal lens [23]. In addition to the thermal lens, the population redistribution between the excited and ground state conduction bands also plays an important part in the variation in the refractive index called a population lens [23]. The plausible explanation for such a high value of nonlinear properties reported in this work arises from the use of $\mathrm{cw}$ laser that induces thermal effects that strongly affect the nonlinear properties masking the electronic contribution to the nonlinear properties. The observed asymmetry for close $z$-scan is an indication of the thermal effect.

\section{Conclusions}

Nanoparticles such as $\mathrm{Au}, \mathrm{Ag}$, (shell- core) Cur-Au, Cur-Ag, and $\mathrm{Au}-\mathrm{Ag}$ were prepared using chemical reduction methods. Both trisodium citrate and curcumin were used as reducing agents. The main significant aspect of the green synthesis procedure is that the maintenance of $\mathrm{pH}$ during the synthesis process is not required. The SPRs in the nanoparticle is 
confirmed by measuring visible spectra using a UV-Vis spectrometer. For Au nanoparticles, the particle size distribution was determined using TEM. Nanoparticle size distribution was estimated by comparing the calculations from Mie theory and experimental absorption spectra. Z-scan technique was used to measure the nonlinear properties of nanoparticles. The nonlinear refractive index and nonlinear absorption of these samples were measured using the $\mathrm{z}$-scan technique with $\mathrm{cw}$ argon-ion laser beam at $488 \mathrm{~nm}$ and $514 \mathrm{~nm}$. Both SA absorption and RSA were observed and found to be dependent on the sample property.

\section{Competing Interests}

The authors declare that they have no competing interests.

\section{References}

[1] S. Horikoshi and N. Serpone, "Introduction to nanoparticles," in Microwaves in Nanoparticle Synthesis, pp. 1-24, Wiley-VCH, Weinheim, Germany, 2013.

[2] M. J. Bloemer, J. W. Haus, and P. R. Ashley, "Degenerate fourwave mixing in colloidal gold as a function of particle size," Journal of the Optical Society of America B, vol. 7, no. 5, pp. 790795, 1990.

[3] P. Klemm, T. Haug, S. Bange, and J. M. Lupton, "Time-domain interferometry of surface plasmons at nonlinear continuum hot spots in films of silver nanoparticles," Physical Review Letters, vol. 113, no. 26, Article ID 266805, 2014.

[4] M. Sheik-Bahae, A. Said, T. Wei, D. Hagan, and E. Van Stryland, "Sensitive measurement of optical nonlinearities using a single beam," IEEE Journal of Quantum Electronics, vol. 26, no. 4, pp. 760-769, 1990.

[5] E. W. Van Stryland, M. Sheik-Bahae, A. A. Said, and D. J. Hagan, "Characterization of nonlinear optical absorption and refraction," Progress in Crystal Growth and Characterization of Materials, vol. 27, no. 3-4, pp. 279-311, 1993.

[6] F. Z. Henari and A. A. Dakhel, "Linear and nonlinear optical properties of gold nanoparticle-Eu oxide composite thin films," Journal of Applied Physics, vol. 104, no. 3, Article ID 033110, 2008.

[7] D. Rativa, R. E. de Araujo, and A. S. L. Gomes, "One photon nonresonant high-order nonlinear optical properties of silver nanoparticles in aqueous solution," Optics Express, vol. 16, no. 23, pp. 19244-19252, 2008.

[8] E. Shahriari, W.M. M. Yunus, K. Naghavi, and E. Saion, "The optical nonlinearity of au and ag nanoparticle prepared by the $\gamma$ radiation method," American Journal of Engineering and Applied Sciences, vol. 3, no. 2, pp. 260-264, 2010.

[9] M. H. Majles Ara, Z. Dehghani, R. Sahraei, and G. Nabiyouni, "Non-linear optical properties of silver nanoparticles prepared by hydrogen reduction method," Optics Communications, vol. 283, no. 8, pp. 1650-1653, 2010.

[10] A. D. McFarland and C. L. Haynes, Mirkin RPVD and HAG. Citrate Synthesis of Gold Nanoparticles-MRSEC Education, University of Wisconsin-Madison, 2004, http://education.mrsec.wisc.edu/277.htm.

[11] A. P. B. Dackiw, "Induction and modulation of monocyte i macrophage tissue factorifibrin deposition and tnf secretion in the microenvironment of inflammation: the role of tyrosine phosphorylation," PP. 1-14, 1998.
[12] K. Sindhu, A. Rajaram, K. J. Sreeram, and R. Rajaram, "Curcumin conjugated gold nanoparticle synthesis and its biocompatibility," RSC Advances, vol. 4, no. 4, pp. 1808-1818, 2014.

[13] A. A. El-Kheshen and S. F. G. El-Rab, "Effect of reducing and protecting agents on size of silver nanoparticles and their antibacterial activity," Der Pharma Chemica, vol. 4, no. 1, pp. 53-65, 2012.

[14] Ratyakshi and R. P. Chauhan, "Colloidal synthesis of silver nano particles," Asian Journal of Chemistry, vol. 21, no. 10, pp. S113S116, 2009.

[15] E. Kirubha and P. K. Palanisamy, "Green synthesis, characterization of Au-Ag core-shell nanoparticles using gripe water and their applications in nonlinear optics and surface enhanced Raman studies," Advances in Natural Sciences: Nanoscience and Nanotechnology, vol. 5, no. 4, Article ID 045006, 2014.

[16] Y. Xia and N. J. Halas, "Shape-controlled synthesis and surface plasmonic properties of metallic nanostructures," MRS Bulletin, vol. 30, no. 5, pp. 338-348, 2005.

[17] A. Šileikaitè, I. Prosyčevas, J. Puišo, A. Juraitis, and A. Guobienė, "Analysis of silver nanoparticles produced by chemical reduction of silver salt solution," Sileikaitè A, vol. 12, no. 4, 2006.

[18] L. A. Bumm, Size Determination of Gold Nanoparticles using Mie Theory and Extinction Spectra, pp. 1-10, 2007, http://www.nhn.ou.edu/ bumm/NanoLab/pdf/Au_NP_spectrophotometery_activity.pdf.

[19] M. Sheik-Bahae, A. A. Said, T.-H. Wei, D. J. Hagan, and E. W. Van Stryland, "Sensitive measurement of optical nonlinearities using a single beam," IEEE Journal of Quantum Electronics, vol. 26, no. 4, pp. 760-769, 1990.

[20] E. Shahriari, M. Moradi, and M. G. Varnamkhasti, "Investigation of nonlinear optical properties of Ag nanoparticles," International Journal of Optics and Photonics, vol. 9, no. 2, pp. 107-114, 2015.

[21] N. K. M. Naga Srinivas, S. Venugopal Rao, and D. Narayana Rao, "Saturable and reverse saturable absorption of Rhodamine B in methanol and water," Journal of the Optical Society of America B, vol. 20, no. 12, pp. 2470-2479, 2003.

[22] U. Gurudas, E. Brooks, D. M. Bubb, S. Heiroth, T. Lippert, and A. Wokaun, "Saturable and reverse saturable absorption in silver nanodots at $532 \mathrm{~nm}$ using picosecond laser pulses," Journal of Applied Physics, vol. 104, no. 7, Article ID 073107, 2008.

[23] C. Jacinto, D. N. Messias, A. A. Andrade, S. M. Lima, M. L. Baesso, and T. Catunda, "Thermal lens and Z-scan measurements: thermal and optical properties of laser glasses-a review," Journal of Non-Crystalline Solids, vol. 352, no. 32-35, pp. 3582-3597, 2006. 

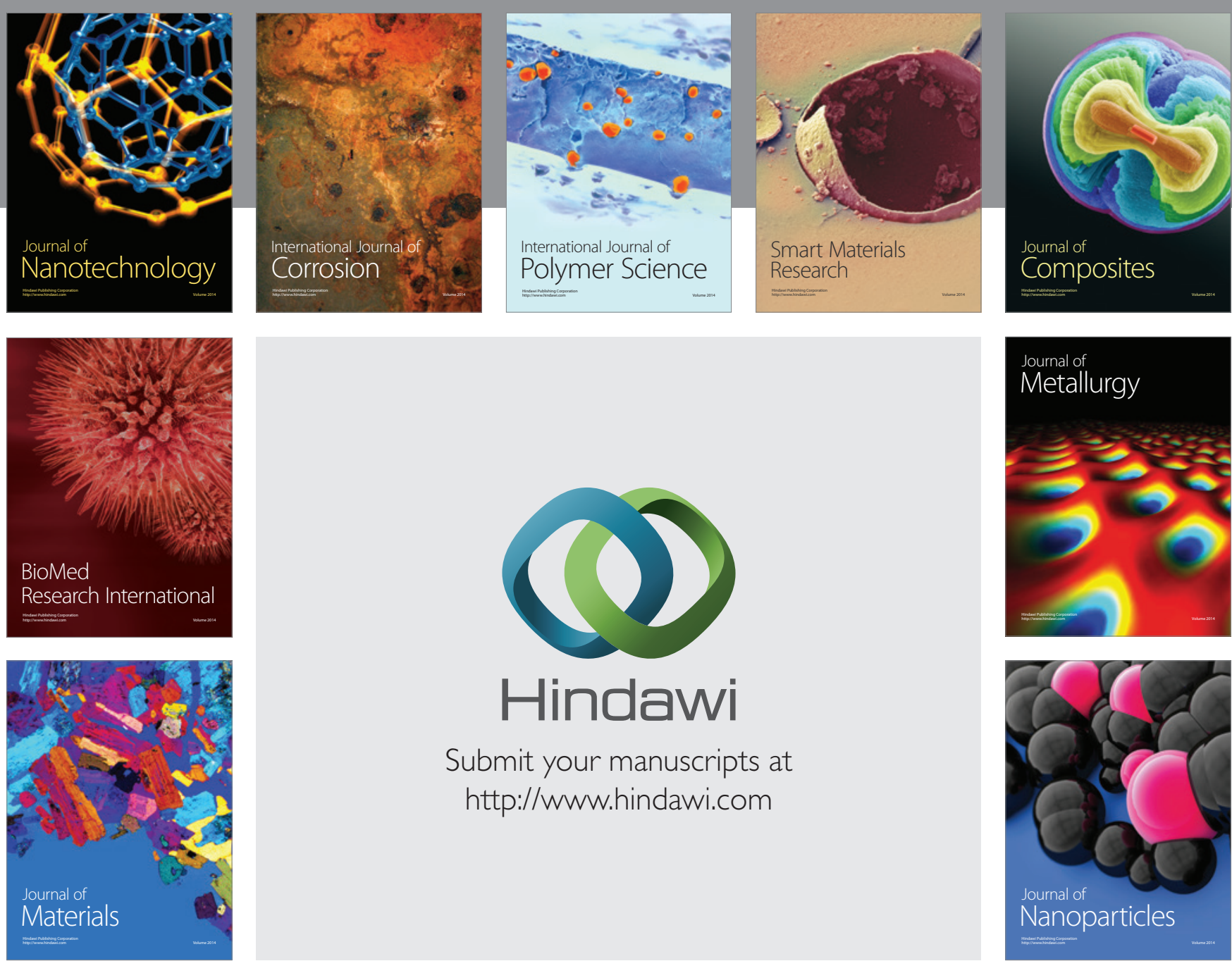

\section{Hindawi}

Submit your manuscripts at

http://www.hindawi.com

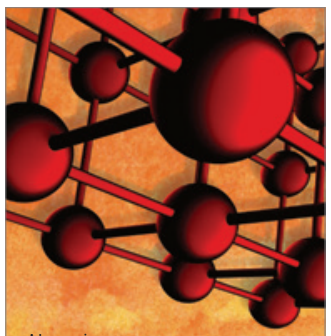

Materials Science and Engineering
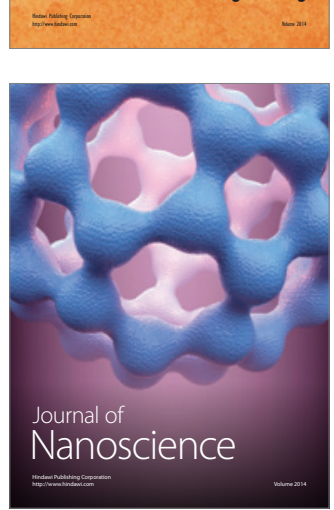
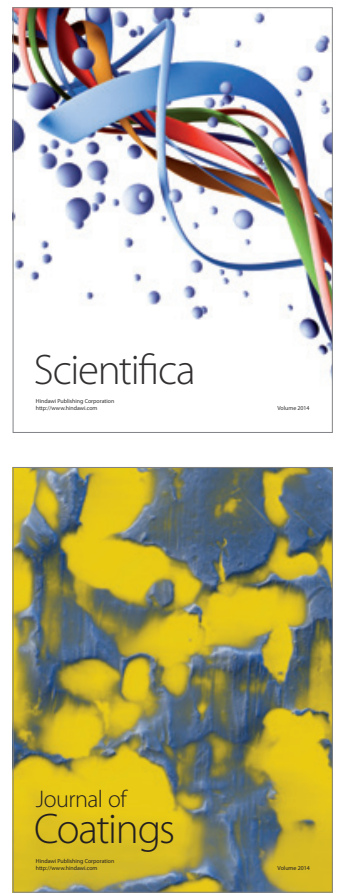
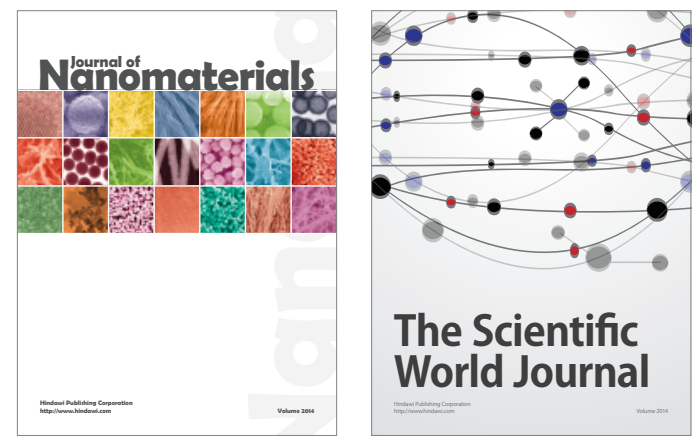

The Scientific World Journal
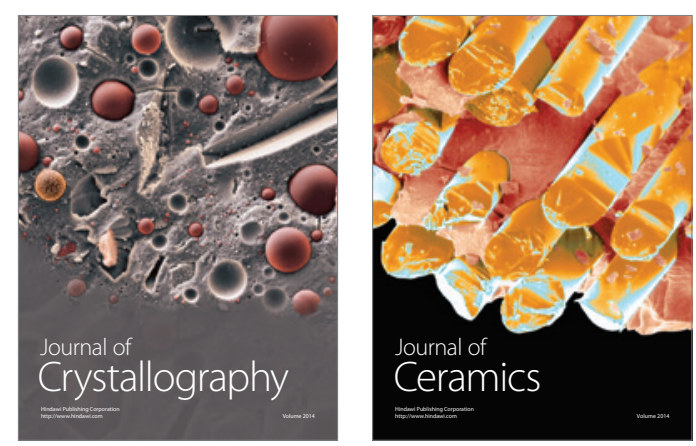
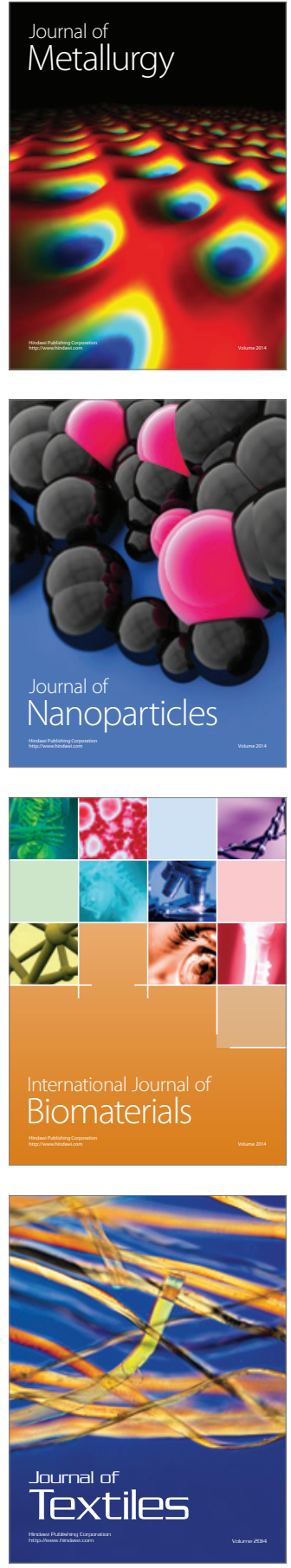